\title{
Mcl-1 Inhibition: Managing Malignancy in Multiple Myeloma
}

\author{
Omar S. Al-Odat ${ }^{1,2}$, Max von Suskil ${ }^{1,2}$, Robert J. Chitren ${ }^{1,2}$, Weam O. Elbezanti ${ }^{1,3}$, \\ Sandeep K. Srivastava ${ }^{4}$, Tulin Budak-Alpddogan ${ }^{3}$, Subash C. Jonnalagadda ${ }^{2}$, \\ Bharat B. Aggarwal ${ }^{5}$ and Manoj Pandey ${ }^{1 *}$
}

${ }^{1}$ Department of Biomedical Sciences, Cooper Medical School of Rowan University, Camden, NJ, United States, ${ }^{2}$ Department of Chemistry and Biochemistry, Rowan University, Glassboro, NJ, United States, ${ }^{3}$ Department of Hematology, Cooper Health University, Camden, NJ, United States, ${ }^{4}$ Department of Biosciences, Manipal University Jaipur, Jaipur, India, ${ }^{5}$ Inflammation Research Center, San Diego, CA, United States

OPEN ACCESS

Edited by:

Raghuram Kandimalla, James Graham Brown Cancer Center, United States

Reviewed by:

Chong Teik Tan, National University of Singapore, Singapore Suman Kumar Samanta, Institute of Advanced Study in Science and Technology, India

*Correspondence: Manoj Pandey pandey@rowan.edu

Specialty section: This article was submitted to Pharmacology of Anti-Cancer Drugs, a section of the journal Frontiers in Pharmacology

Received: 23 April 2021 Accepted: 24 June 2021 Published: 19 July 2021

Citation:

Al-Odat OS, von Suskil M, Chitren RJ, Elbezanti WO, Srivastava SK Budak-Alpddogan T, Jonnalagadda SC, Aggarwal BB and Pandey M (2021) Mcl-1 Inhibition: Managing Malignancy in Multiple Myeloma.

Front. Pharmacol. 12:699629. doi: 10.3389/fphar.2021.699629
Multiple myeloma (MM) is a plasma cells neoplasm. The overexpression of Bcl-2 family proteins, particularly myeloid cell leukemia 1 (Mcl-1), plays a critical role in the pathogenesis of $\mathrm{MM}$. The overexpression of $\mathrm{Mcl}-1$ is associated with drug resistance and overall poor prognosis of MM. Thus, inhibition of the Mcl-1 protein considered as a therapeutic strategy to kill the myeloma cells. Over the last decade, the development of selective Mcl-1 inhibitors has seen remarkable advancement. This review presents the critical role of $\mathrm{Mcl}-1$ in the progression of $\mathrm{MM}$, the most prominent $\mathrm{BH} 3$ mimetic and semi- $\mathrm{BH} 3$ mimetic that selectively inhibit Mcl-1, and could be used as single agent or combined with existing therapies.

Keywords: multiple myeloma, drug resistant, Mcl-1, Bcl-2 homology 3 mimetics, apoptosis

\section{INTRODUCTION}

The innate and adaptive immune system comprises several different types of cells that elegantly work together to stave off infection and remove transformed or damaged cells. Lymphocytes including both $\mathrm{T}$ - and B-cells are among the most important cellular category within the immune system. The plasma cells are a type of unique B cells that reside in the bone marrow (BM) and secrete an antibody corresponding to the antigen. When these plasma cells begin proliferating out of control, they can build up within the BM and form numerous tumors across the body (Figure 1). This type of neoplasms is called Multiple Myeloma (MM) and considered the second most common hematologic malignancy, accounting around $12 \%$ of hematological malignancies (Kazandjian, 2016). MM is slightly more common among older men, with the median age of 65 years, and it is rarely diagnosed in younger people (Kumar et al., 2008; Gerecke et al., 2016; Naymagon and Abdul-Hay, 2016). Depending on the stage of disease, symptoms of MM begin with abnormalities in the bone and calcium homeostasis, low blood cell counts, renal insufficiency, and multiple infections. Because the symptoms are so generalized, MM is a challenging disease to diagnose. Furthermore, the protective role of the $\mathrm{BM}$ on the proliferating plasma cells make it even more challenging to treat.

In the last several decades the treatment options for MM have dramatically improved, unfortunately, the survival rate is marginal (Bergsagel and Kuehl, 2005). According to the American Cancer Society 2021 estimation, approximately 34,920 new MM cases will be diagnosed (19,320 men and 15,600 women), approximately 12,410 cancer deaths (6,840 men and 5,570 women) from MM alone in the United States (Siegel et al., 2021). Table 1 illustrates the common drugs that have been used to treat MM patients. Most therapeutic approaches to date for MM patients, especially in relapsed/refractory (R/R) cases have been based on combined 


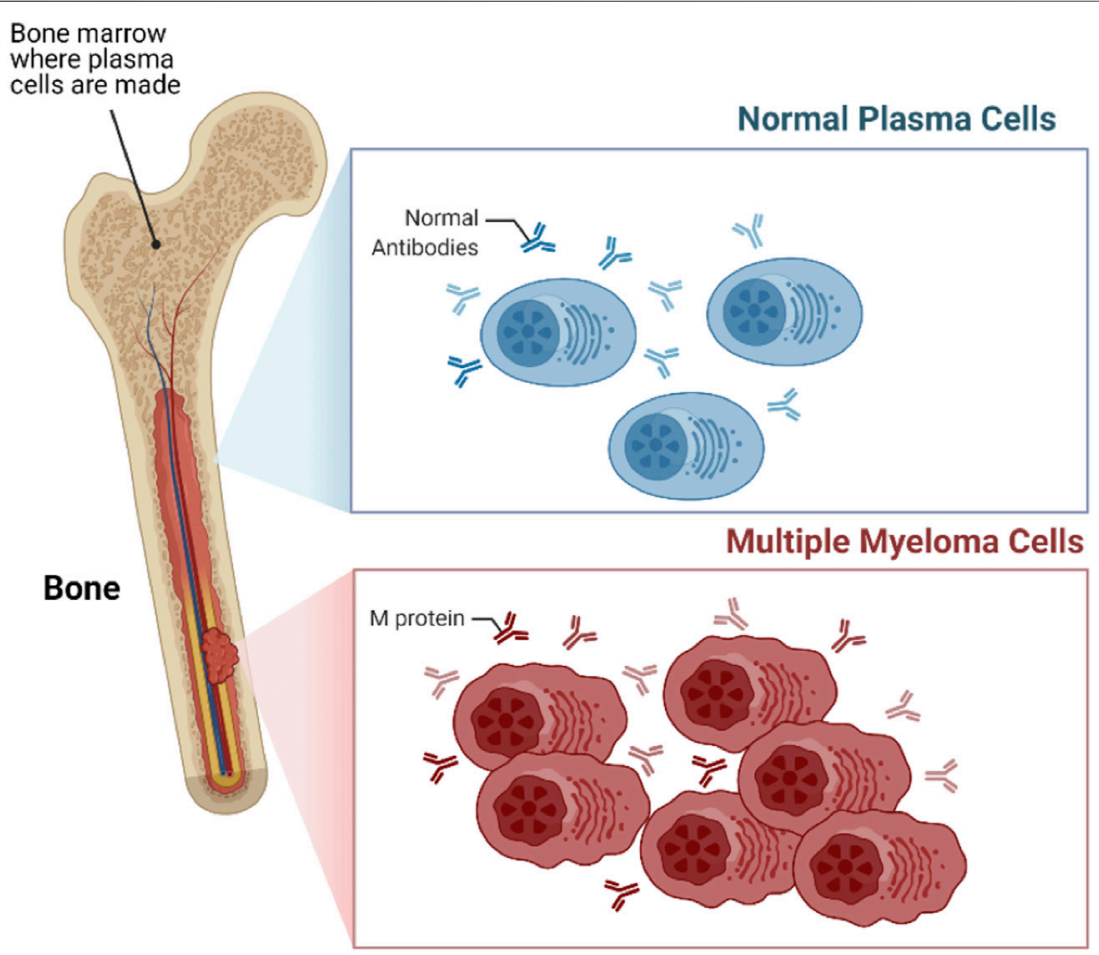

FIGURE 1 | Multiple myeloma (MM). MM is a type of blood cancer that initiates from the bone marrow (BM), arising from the aberrant proliferation of plasma cells.

formulations of available therapies. In spite of the efficacy and diversity of therapeutic approaches, drug resistance is a major challenge as $\mathrm{MM}$ continues to show high rates of relapse and quickly acquired resistance to therapies (Abdi et al., 2013). There are several unanswered questions regarding MM including: what are the causes of progression of MM from its precursor state? Why MM patients instigate to relapse? How MM clones resistant to drugs persist in the presence of effective therapies?

\section{MCL-1 PROTEIN AS A POTENTIAL TARGET FOR MULTIPLE MYELOMA}

Apoptosis is a vital procedure for regular development and maintaining the tissue homeostasis. Mammalian apoptosis occurs via one of two distinct pathways, either the intrinsic or extrinsic pathways (Figure 2). Both the intrinsic and extrinsic pathways end with the activation of a certain group of protease enzymes called Caspase proteins. The intrinsic pathway entails mitochondrial outer membrane permeabilization (MOMP) that regulates directly by interactions between $\mathrm{B}$ cell lymphoma 2 (Bcl-2) family proteins. The Bcl-2 family proteins are critical regulators of apoptosis. The members of this family proteins are divided into three groups according to function: anti-apoptotic proteins (Bcl-2, Mcl-1, Bcl-xL, Bcl-W, and Bfl-1); pro-apoptotic BH3-only proteins (Noxa, Puma, Bim, Bid, Bad, BMF, and Bik); and multi-domain pro-apoptotic proteins (Bax, Bak, and Bok).
Intrinsic pathways like cytokine deprivation or DNA damage promote overexpression and activation of $\mathrm{BH} 3$-only proteins, which stimulate apoptosis in two different ways. First, the $\mathrm{BH} 3-$ only proteins behave as inhibitors of anti-apoptotic proteins by competing for their binding with Bax and Bak proteins (Czabotar et al., 2014; Figure 2). This is accomplished via the amphipathic a-helix of the $\mathrm{BH} 3$ domain that contains four hydrophobic residues (h1-h4) that bind four hydrophobic pockets (P1-P4) within the anti-apoptotic proteins in their $\mathrm{BH} 3$ binding groove (Liang and Fesik, 1997; Czabotar et al., 2007; Stewart et al., 2010). For example, Noxa selectively inhibits Mcl-1 with high affinity binding thereby indirectly activating the Bax/Bak pathway (Smith et al., 2011; Kale et al., 2018). Simultaneously, BH3-only proteins can also result in the direct activation of multi-domain proapoptotic proteins Bax and Bak, which cause MOMP, leading to release of Cytochrome $\mathrm{C}$ and SMAC proteins into the cytosol resulting in downstream Caspase activation and ultimately activation of apoptosis (Dewson and Kluck, 2009).

The extrinsic pathway is promoted by death receptors activation. This leads to activation of initiator Caspases 8 and 10 , which can directly induce the downstream executioner Caspase such as Caspase 3 and 7 to drive full commitment to apoptosis (Kaufmann et al., 2012). Moreover, Caspases 8 and Caspase 10 can activate Bid, which in turn activates Bak and Bax to induce MOMP, which is the connecting link between the extrinsic and intrinsic pathways (Kaufmann et al., 2012; Figure 2). 
TABLE 1 | Mechanism of action and Side effects of Common Therapy in MM.

\begin{tabular}{|c|c|c|c|}
\hline Drug & Mechanism of action & Side effects & Ref \\
\hline Melphalan & Chemotherapy drug & Bone marrow damage and chemotherapy side effects & Bergsagel et al. (1962) \\
\hline $\begin{array}{l}\text { Thalidomide } \\
\text { (Thalomid) }\end{array}$ & Immunomodulating agent & $\begin{array}{l}\text { Drowsiness, fatigue, constipation, and painful nerve damage as well } \\
\text { as severe birth defects when taken during pregnancy }\end{array}$ & Singhal et al. (1999) \\
\hline $\begin{array}{l}\text { Bortezomib } \\
\text { (Velcade) }\end{array}$ & Proteasome inhibitor & $\begin{array}{l}\text { Vomiting, tiredness, diarrhea, constipation, decreased appetite, } \\
\text { fever, lowered blood counts and nerve damage }\end{array}$ & Richardson et al. (2003) \\
\hline $\begin{array}{l}\text { Lenalidomide } \\
\text { (Revlimid) }\end{array}$ & $\begin{array}{l}\text { Small molecule analogue of } \\
\text { thalidomide }\end{array}$ & $\begin{array}{l}\text { Drowsiness, fatigue, constipation, and painful nerve damage as well } \\
\text { as severe birth defects when taken during pregnancy }\end{array}$ & $\begin{array}{l}\text { Hideshima et al. (2000), Rajkumar et al. } \\
\text { (2005), Richardson et al. (2002) }\end{array}$ \\
\hline $\begin{array}{l}\text { Carfilzomib } \\
\text { (Kyprolis) }\end{array}$ & Proteasome inhibitor & $\begin{array}{l}\text { Tiredness, nausea, vomiting, diarrhea, shortness of breath, fever and } \\
\text { low blood counts and occasionally more serious problems such as } \\
\text { pneumonia, heart problems, and kidney or liver failure }\end{array}$ & Herndon et al. (2013) \\
\hline $\begin{array}{l}\text { Pomalidomide } \\
\text { (Pomalyst) }\end{array}$ & $\begin{array}{l}\text { Small molecule analogue of } \\
\text { thalidomide }\end{array}$ & $\begin{array}{l}\text { Same thalidomide side effects with a less risk of nerve damage side } \\
\text { effect }\end{array}$ & Lacy et al. (2009) \\
\hline $\begin{array}{l}\text { Panobinostat } \\
\text { (Farydak) }\end{array}$ & $\begin{array}{l}\text { Oral Histone deacetylase } \\
\text { (HDAC) inhibitor }\end{array}$ & $\begin{array}{l}\text { Feeling tired, weakness, nausea, diarrhea vomiting, loss of appetite, } \\
\text { fever, swelling in the arms or legs, and occasionally altered blood cell } \\
\text { counts and blood electrolytes. Rare cases of internal bleeding, liver } \\
\text { damage, and changes in heart rhythm which can sometimes be life } \\
\text { threatening }\end{array}$ & Laubach et al. (2015) \\
\hline Ixazomib (Ninlaro) & Oral proteasome inhibitor & $\begin{array}{l}\text { Nausea, vomiting, diarrhea, constipation, swelling in the hands or } \\
\text { feet, back pain, lowered blood platelet count and nerve damage }\end{array}$ & Muz et al. (2016) \\
\hline $\begin{array}{l}\text { Daratumumab } \\
\text { (Darzalex) }\end{array}$ & $\begin{array}{l}\text { Intravenous monoclonal } \\
\text { antibody }\end{array}$ & $\begin{array}{l}\text { Coughing, wheezing, trouble breathing, throat tightness, runny nose, } \\
\text { nasal congestion, feeling dizzy or lightheaded, headache, rash, } \\
\text { nausea, fatigue, back pain, fever, and lower blood cell counts }\end{array}$ & Lokhorst et al. (2015) \\
\hline $\begin{array}{l}\text { Elotuzumab } \\
\text { (Empliciti) }\end{array}$ & $\begin{array}{l}\text { Intravenous monoclonal } \\
\text { antibody }\end{array}$ & $\begin{array}{l}\text { Chills, feeling dizzy or lightheaded, wheezing, trouble breathing, } \\
\text { cough, tightness in the throat, runny nose, nasal congestion, upper } \\
\text { respiratory tract infections and pneumonia, rash, fatigue, loss of } \\
\text { appetite, diarrhea, constipation, fever, and nerve damage }\end{array}$ & Lonial et al. (2015) \\
\hline Selinexor (Xpovio) & $\begin{array}{l}\text { Oral Nuclear export inhibitor of } \\
\text { XPO1 }\end{array}$ & $\begin{array}{l}\text { Diarrhea, nausea, vomiting, loss of appetite, weight loss, low blood } \\
\text { sodium levels susceptibility to infection, low platelet counts, and low } \\
\text { white blood cell counts }\end{array}$ & Vogl et al. (2018) \\
\hline
\end{tabular}

The mitochondrial membrane engages Mcl-1 with other Bcl-2 family partners for initiation of apoptosis. The interaction between the family members determine the outcome (Kale et al., 2018). Mcl-1 has a diverse localization within human cells. It is primarily found within the mitochondrial outer and inner membranes (Yang et al., 1995). However, studies have reported its localization in the nucleus and cytoplasm of polymorphonuclear leukocytes (PMNs) (Leuenroth et al., 2000). How different localization affects the function and its stability is not known.

The studies of Kozopas et al. first proved a high Mcl-1 expression in a differentiating human myeloid leukemia ML-1 cell line (Kozopas et al., 1993). Subsequently, it was shown to be expressed in several different cells as well. The MM cells exhibit imbalances in their anti-apoptotic proteins expression levels, especially Mcl-1 that leads to defects in the mitochondrial intrinsic pathway (Derenne et al., 2002; Zhang et al., 2002). In order to prevent apoptosis and allow continued cell growth, Mcl1 forms a heterodimer protein-protein interaction with multidomain pro-apoptotic proteins Bax and Bak (Sedlak et al., 1995; Willis and et al., 2005). Mcl-1 is known to be highly expressed in MM cells and plays a pivotal role in MM initiation, progression, and apoptosis resistance (Derenne et al., 2002; Zhang et al., 2002). Newly diagnosed cases of MM have continued to show increasing Mcl-1 protein expression, which predicts a higher relapse and poor patient survival rate (Wuillème-Toumi et al., 2005). Thus, $\mathrm{Mcl}-1$ is an attractive therapeutic target for MM.

\section{REGULATION OF MCL-1 PROTEIN}

The interaction of myeloma cells to $\mathrm{BM}$ microenvironment (BMM) is the hall mark of MM (Figure 3). Additionally, MM cells receive crucial signals from the BMM that help them to evade apoptosis in order to maintain their long-term survival. The BM stromal cells (BMSCs) regulate the anti-apoptotic Bcl-2 family proteins by secreting a group of signaling cues. Mcl-1 is regulated through several extracellular signaling molecules including interleukins (IL-3, IL-5, and IL-6) (Wang et al., 1999; Huang et al., 2000; Jourdan et al., 2000); growth factors such as vascular endothelial growth factor (VEGF), epidermal growth factor (EGF) (Leu et al., 2000; Le Gouill et al., 2004); granulocyte macrophage colony stimulating factors (GM-CSF) (Chao et al., 1998); and interferon alpha (INF-a) (Jourdan et al., 2000). Combined, these stimuli trigger and modulate multiple signaling pathways including Janus kinase/signal transducer and activator of transcription (JAK/STAT), rat sarcoma/mitogenactivated protein kinase (Ras/MAPK), MEK/extracellular signal-related kinase (ERK) as well as phosphatidylinositol-3 kinase (PI3-K)/Akt (Figure 3).

The cytokine IL-6 is a main survival factor for MM cells (Klein et al., 1995). IL-6 triggers the upregulation of Mcl-1, Bcl-xL, and VEGF via stimulation of the JAK/STAT-3 signaling pathway (Puthier et al., 1999; Dankbar et al., 2000). In turn, VEGF promotes IL-6 induction in neighboring BM cells (BMCs) (Dankbar et al., 2000). Furthermore, IL-6 induces survival of 


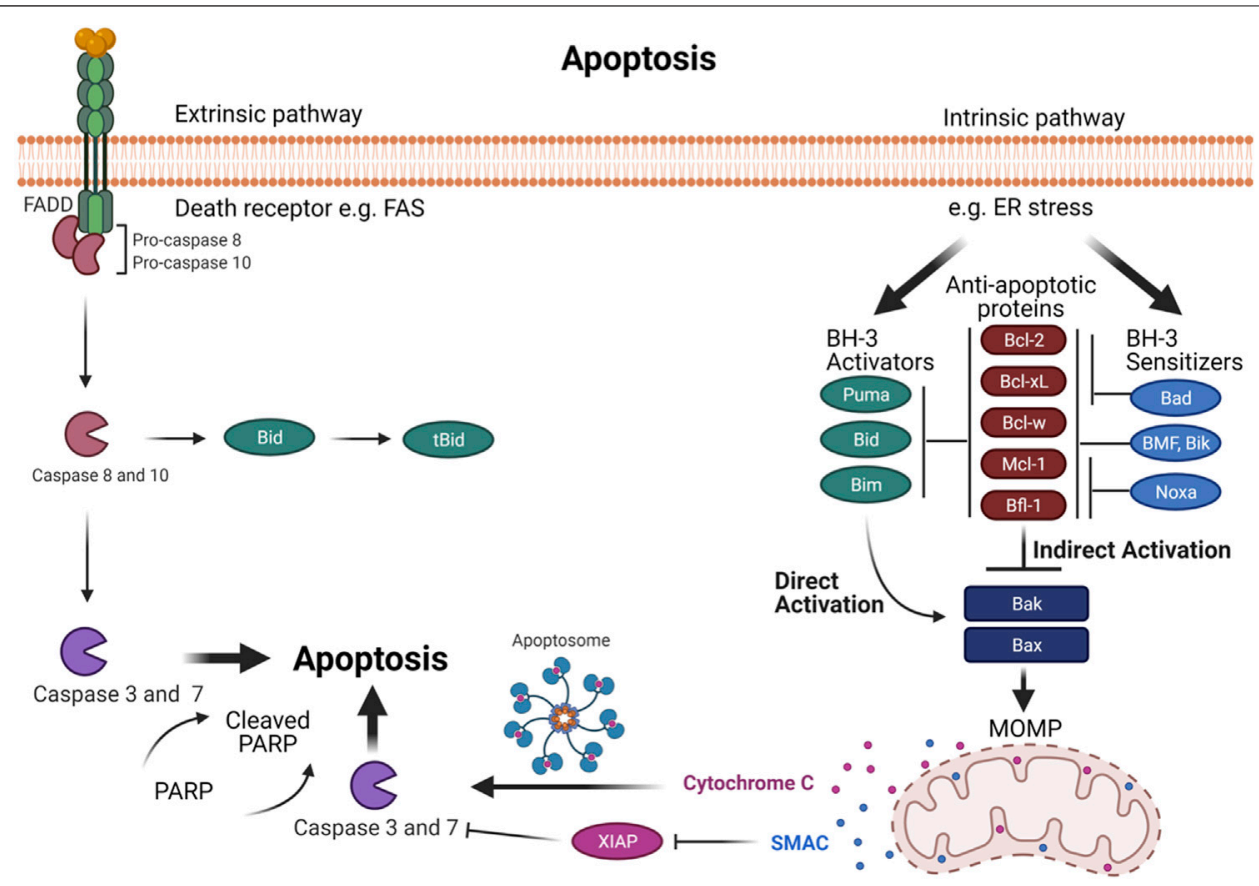

FIGURE 2 | The programmed cell death- via intrinsic and extrinsic pathways in normal mammalian cells. Intrinsic and extrinsic pathways result in the activation of a family of protease enzymes called Caspase proteins. The intrinsic pathway is promoted by cellular stresses that modulate Bcl-2 family proteins and activates Bak and Bax. In the indirect activation, upregulation of BH3-only proteins will act as inhibitors of anti-apoptotic proteins by competing for their binding with Bax and Bak proteins, leading Bax and Bak to oligomerize. In the direct activation, upregulation of BH3 activators proteins directly activates Bax and Bak. This activation leads to mitochondrial outer membrane permeabilization (MOMP), subsequently Cytochrome $\mathrm{C}$ and SMAC proteins release into the cytosol, causing the downstream of Caspase activation that ends with apoptosis. The extrinsic pathway is promoted by death receptors activation. This leads to activation of initiator Caspases 8 and 10 , which can regulate the downstream executioner Caspase such as Caspase 3 and 7 to drive full commitment to apoptosis. Moreover, Caspases 8 and 10 can activate Bid, which in turn activates Bak and Bax to induce MOMP which establishes the link between the extrinsic and intrinsic pathways.

MM cells via stimulating the Ras/MAPK pathway, which engage in Mcl-1 overexpression (Ogata et al., 1997). Additionally, IFN-a induces Mcl-1 in a STAT-3 dependent manner (Jourdan et al., 2000). Furthermore, the tumor necrosis factor (TNF) family including $\mathrm{B}$ cell activating factor (BAFF), a proliferationinducing ligand (APRIL) prevent apoptosis by inducing the expression of Mcl-1 and Bcl-2 (Moreaux et al., 2004). Insulin like growth factor 1 (IGF-1) affects the cell survival, by downregulating pro-apoptotic protein Bim (De Bruyne et al., 2010). The imbalance between Bim and Mcl-1 expression plays an important role in MM cell survival (Gomez-Bougie et al., 2004). The transcription factors such as B lymphocyte induced maturation protein 1 (Blimp-1), X-box binding protein 1 (XBP1 ), and interferon regulatory factor 4 (IRF4) are critical for myeloma cells differentiation and development (Calame et al., 2003). The Blimp-1 downregulates the expression of proapoptotic protein Bim (Lin et al., 2007).

Mcl-1 and other anti-apoptotic proteins contain four Bcl-2 homology $(\mathrm{BH})$ domains (BH1-3 domains interact to form a hydrophobic cleft termed "BH3-binding groove"), and a C-terminal tail of hydrophobic transmembrane domain (TM) that permeates into the mitochondrial membrane (Kozopas et al., 1993). Interestingly, compared to the other anti-apoptotic proteins, Mcl-1 has several unique properties including unique binding site, size, half-life, and localization. Mcl-1 has a shallow, relatively inflexible and more electropositive binding site abundant in lysine and histidine residues (Denis et al., 2020). Bcl-2 and Bcl-xL proteins contain 233 amino acids, whereas Mcl1 protein contains 350 amino acids. This size difference is due to the presence of a large $\mathrm{N}$-terminal domain of four PEST sequences [amino acids sequence extensive in proline $(\mathrm{P})$, glutamic acid (E), serine (S), and threonine (T)] (Kozopas et al., 1993; Thomas et al., 2010), which can target Mcl-1 for degradation through the ubiquitin-proteasome system (UPS) and renders it short half-life (usually less than three hours depending on the cellular conditions) (Rogers et al., 1986; Kozopas et al., 1993; Yang et al., 1995).

In MM, the Mcl-1 gene is the most important and selective of the survival genes (Tiedemann et al., 2012). Gene coding of Mcl-1 is located on chromosome 1q21 region. Approximately $40 \%$ of MM cases have shown chromosomal amplification of 1q21, hence increased Mcl-1 expression (Shah et al., 2018; Slomp et al., 2019). Additionally, the gene coding of cytokine interleukin 6 receptor (IL-6R) is located on the same chromosome region (1q21) (Pawlyn and Morgan, 2017). The coding region of Mcl-1 contains three exons and two introns that undergoes alternative splicing to produce mature RNA (mRNA) isoforms. The Mcl-1L (Mcl-1 long) splice variant joins the three exons, has a full length of 350 amino acids and acts as an anti-apoptotic. On the other hand, Mcl-1S (Mcl-1 short) joins 


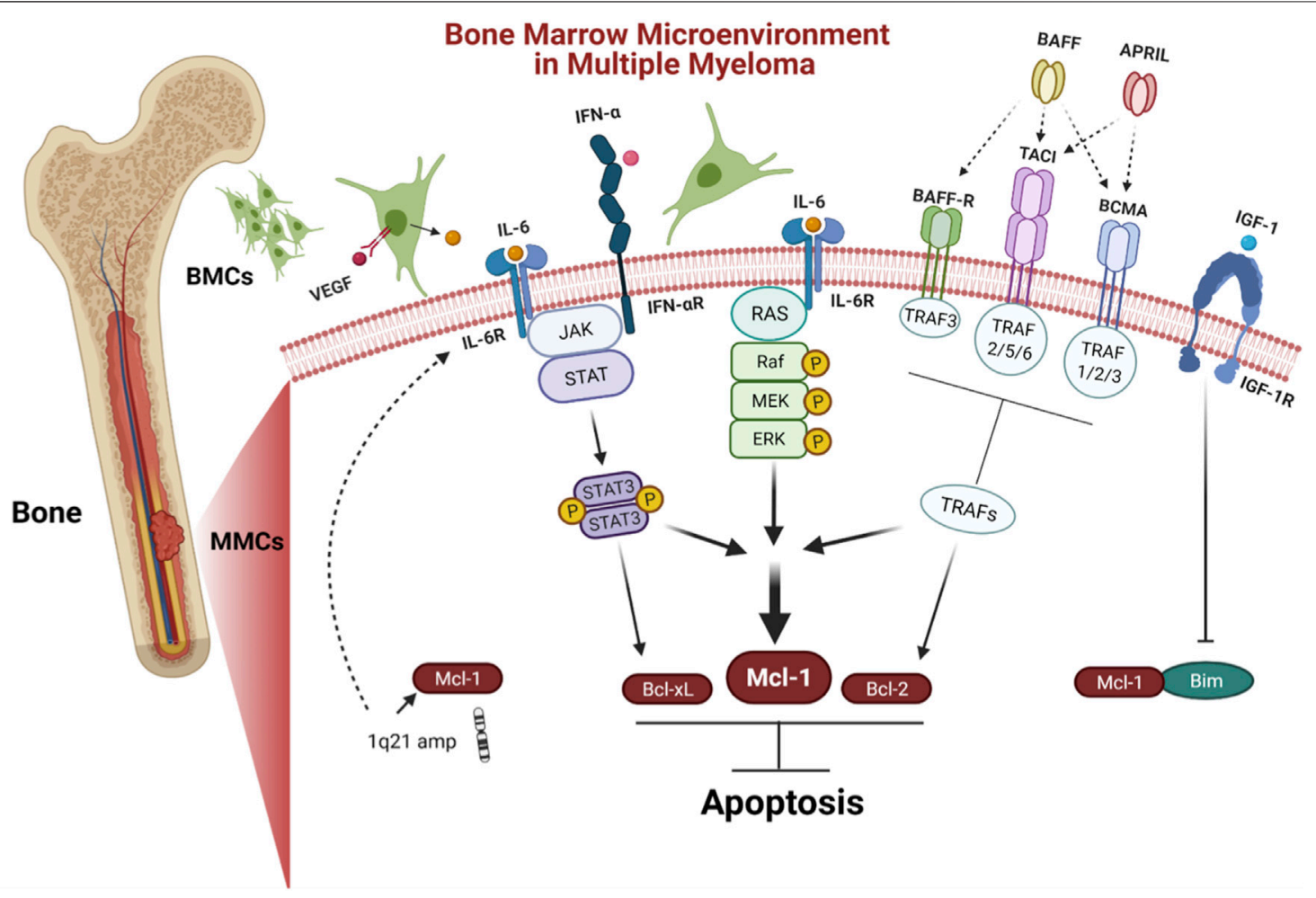

FIGURE 3 | Bone marrow microenvironment (BMM) in MM. BMM facilitates the long term survival of MM. Stromal cells in BM regulate anti-apoptotic proteins by secreting a variety of signaling molecules including IL-6 and IFN- $\alpha$ that trigger JAK/STAT pathway, leading to the upregulation of Mcl-1, Bcl-XL, and VEGF. VEGF promotes IL-6 induction in neighboring BMCs. Furthermore, IL-6 induces survival of MM cells via Ras/MAPK pathway, which modulates the expression of Mcl-1 The tumor necrosis factor (TNF) family including BAFF and APRIL are other stimuli from the BMM that induce expression of both Mcl-1 and Bcl-2 via tumor necrosis factor receptor-associated factors (TRAFs) including BAFF-R, BCMA, and TACI. IGF-1 is another stimulus that acts by downregulating Bim, leading to release Mcl-1. MM cases have shown chromosomal amplification of 1q21 region, where the gene coding for Mcl-1 and IL-6R are located.

only the first and the third exons without the central exon, with length of 271 amino acids, shows increased cytosolic localization and lacks the $\mathrm{BH} 1, \mathrm{BH} 2$ and $\mathrm{TM}$ domains but has the $\mathrm{BH} 3$ domain which plays a critical pro-apoptotic role (Bae et al., 2000; Bingle et al., 2000). Interestingly, Kim et al. (2009), found a new alternative splicing variant detected in the mitochondrion termed Mcl-1ES (Mcl-1 extra short) with a shorter length of 197 amino acids due to an absence of PEST sequences (Kim et al., 2009). $\mathrm{Mcl}-1 \mathrm{ES}$ forms an interaction with Mcl-1L in order to induce apoptosis (Kim et al., 2009).

The post transcriptional regulation of $\mathrm{Mcl}-1$ is complex and controlled by multiple RNA binding proteins (RPBs) and microRNAs (miRNAs). For example, Mcl-1 has been shown to be downregulated in MM by miR-29b, miR-137, and miR-197 that leads to apoptosis (Zhang et al., 2011; Yang et al., 2015; Cui and Placzek, 2018). Additionally, at the post-translational level, the large $\mathrm{N}$-terminal domain PEST allows for non-proteasomal degradation via cleavage (Herrant et al., 2004), proteasomal degradation via phosphorylation (Thomas et al., 2010), and ubiquitination (Mojsa et al., 2014), which further impact Mcl1 expression, stability, localization, and function. Mcl-1 PEST undergoes Caspase cleavage at two different sites, located at Asp127 that produce $\mathrm{Mcl}-1^{1-127}$ associated with $\mathrm{Mcl}-1^{128-350}$. At Asp158 that produce Mcl- ${ }^{1-157}$ associated with Mcl-1 ${ }^{158-350}$
(Herrant et al., 2004). Interestingly, not all Mcl-1 cleavage fragments revoke anti-apoptotic function. Mcl-1 $\Delta 127$ fragment has anti-apoptotic function same as Mcl-1 and exists mainly in the cytoplasm and sequester BH3-only or Bak in order to prevent apoptosis (Wang and et al., 2020).

The Mcl-1 phosphorylation plays a critical role in controlling Mcl-1 function as well. Mcl-1 phosphorylation occurs by several protein kinases including; c-Jun N-terminal kinase (JNK) (Inoshita et al., 2002), glycogen synthase kinase 3 (GSK-3) (Maurer et al., 2006; Ding et al., 2007), and extracellular signal-regulated kinase (ERK-1) (Domina et al., 2004; Ding et al., 2008). The phosphorylated Mcl-1 proteins have been reported to result in different functions according to phosphorylation sites (Thomas et al., 2010; Senichkin et al., 2020). Furthermore, a reversible form of post-translational ubiquitination controls several aspects of Mcl-1 including stability and proteasomal degradation and allow for rapid respond to environmental signals in order to change cell state from survival to apoptosis. The Mcl-1 ubiquitin-proteasome system is mediated by five different E3 ubiquitin-ligases including Mcl-1 ubiquitin ligase E3 (Mule) (Zhong et al., 2005), SCF beta-transducin repeats containing protein $\left(\mathrm{SCF}^{\beta-\mathrm{TrCP}}\right.$ ) (Ding et al., 2007), SCF F-box and WD repeat domain containing 7 (SCF $\left.{ }^{\mathrm{Fbw7}}\right)$ (Inuzuka et al., 2011), 


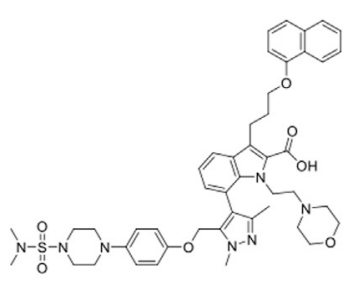

A-1210477

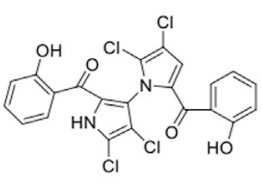

Maritoclax

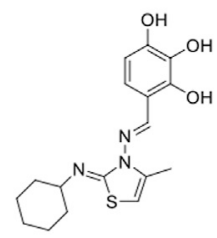

MIM1

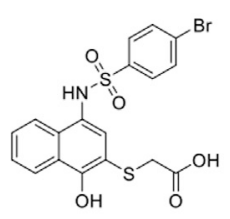

UMI-77

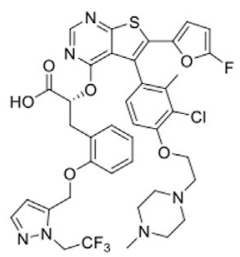

S63845

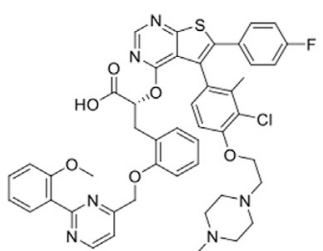

S64315 or MIK666

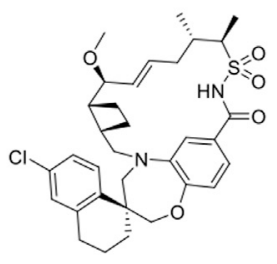

AMG-176

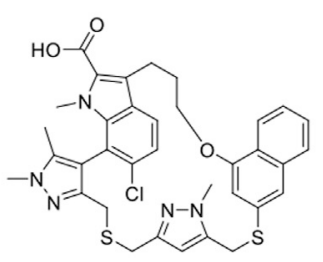

AZD5991

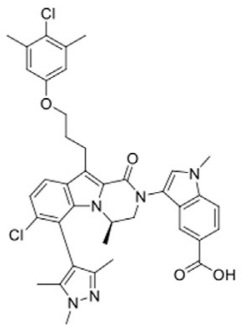

VU661013

FIGURE 4 | Chemical structures of selective Mcl-1 inhibitors. The most prominent Mcl-1 inhibitors including A-1210477, Maritoclax, MIM1, UMI-77, S63845, S64315/MIK666, AMG-176, AZD5991, and VU661013.

anaphase-promoting complex/cyclosome (APC/CC ${ }^{\mathrm{dc} 20}$ ) (Harley et al., 2010), and tripartite motif containing 17 (Trim17) (Magiera et al., 2013). Furthermore, the ubiquitin-proteasome system contains an additional deubiquitinase called ubiquitin specific peptidase 9, X-linked (USP9X) that removes poly-ubiquitin chains leading to stabilize Mcl-1 and prevent apoptosis (Schwickart et al., 2010). The degree of ubiquitination is also subject to variation based upon the variable phosphorylation of residues of Mcl-1 (Maurer et al., 2006; Ding et al., 2007). Our understanding of $\mathrm{Mcl}-1$ regulations has been greatly expanded by the findings that have developed over the years and provide deep critical insights into exactly how Mcl-1 protein plays such a key role in cellular apoptosis as well as how it can be modulated to provide new options of potential therapeutic approach in $\mathrm{MM}$ and other Mcl-1 dependent cancers.

\section{DEVELOPMENT OF SELECTIVE MCL-1 INHIBITORS}

Studies have demonstrated that MM depends on Mcl-1 proteins for survival, prognosis, and chemo resistance. Thus, inhibition of Mcl-1 offers an attractive target and a promising strategy for myeloma treatment. Nonetheless, the targeting of Mcl-1 has been challenging because of its complex regulation. So far, two approaches have been adopted to inhibit Mcl-1, one is direct inhibition and second is indirect targeting. The indirect targeting is a less selective method inhibits other anti-apoptotic proteins, may have more serious side effects. Whereas, direct Mcl-1 inhibitors target the hydrophobic cleft $\mathrm{BH} 3$-binding groove of BH3-only proteins interactions domain. Therefore, these inhibitors are very specific to $\mathrm{Mcl}-1$. Here we will review BH3- mimetic inhibitors that selectively bind Mcl-1. The structure of these inhibitors are shown in Figure 4. The current status of development of these agents are summarized in Table 2.

\section{Indole-2-Carboxylic Acids Analog (A-1210477)}

This was developed by AbbVie in 2008. A-1210477 induces intrinsic apoptosis pathway by selectively inhibiting $\mathrm{Mcl}-1$ with high binding affinity $(\mathrm{Ki}=0.454 \mathrm{nM})$ (Leverson and et al., 2015). Upon binding, BH3 mimetic A-1210477 results in an accumulation of $\mathrm{Mcl}-1$ protein by preventing its degradation. A-1210477 disrupts the Mcl-1:Bim and Mcl-1: Noxa complexes in order to induce Bax/Bak- dependent MOMP, leading to Cytochrome $\mathrm{C}$ release and Caspase activation (Leverson and et al., 2015). The treatment of A1210477 decreased the association of Mcl-1: Bak complex within an hour, however the complex was totally disrupted after three hours of treatment (Gomez-Bougie et al., 2018). Interestingly, the studies of Mallick et al. (2019) showed that A-1210477 induces rapid apoptosis within $0.5-1 \mathrm{~h}$ of treatment, without inducing Noxa (Mallick and et al., 2019). A-1210477 as a monotherapy or in a combination with Navitoclax resulted in death of different cell lines including MM, melanoma, and nonsmall cell lung cancer cell lines that were found to be Mcl-1 dependent by $\mathrm{BH} 3$ profiling or siRNA rescue experiments (Leverson and et al., 2015; Mukherjee and et al., 2018). This finding was reinforced by the efficacy of A-1210477 as a combination with Venetoclax against acute myeloid leukemia (AML) (Fiskus and et al., 2019). A-1210477 inhibited triple negative breast cancer cell line growth activity in vitro which 
TABLE 2 | Direct Mcl-1 Inhibitors BH3 Mimetic and semi BH3 Mimetic drugs.

\begin{tabular}{|c|c|c|c|}
\hline $\begin{array}{l}\text { Mcl-1 } \\
\text { inhibitor }\end{array}$ & Company & Affinity & Clinical trial status \\
\hline A-1210477 & Abbive & $\mathrm{Ki}=0.45 \mathrm{nM}$ & Preclinical \\
\hline Maritoclax & $\begin{array}{l}\text { Hong-Gang Wang's group at Pennsylvania } \\
\text { State University }\end{array}$ & IC50 $10 \mu \mathrm{M}$ & Preclinical \\
\hline MIM1 & Cohen and coworkers & $\begin{array}{l}\text { Only at very high } \\
\text { concentration }\end{array}$ & Failed in vivo \\
\hline UMI-77 & $\begin{array}{l}\text { Zaneta Nikolovska-Coleska's group at } \\
\text { University of Michigan }\end{array}$ & $\mathrm{Ki}=490 \mathrm{nM}$ & Preclinical \\
\hline S63845 & Servier and Vernalis & $\mathrm{Kd}=0.19 \mathrm{nM}$ & Preclinical \\
\hline S64315/ & Servier and Vernalis and Novartis & undisclosed & Phase I by Novartis, in R/R lymphoma or R/R MM patients (NCT02992483) \\
\hline MIK666 & & & $\begin{array}{l}\text { Phase I by Servier, in AML and MDS patients (NCT02979366) } \\
\text { Phase I by Servier as a combination of S64315/MIK666 plus Venetoclax in AML } \\
\text { patients (NCT03672695) }\end{array}$ \\
\hline AMG-176 & Amgen & $\mathrm{Ki}=0.06 \mathrm{nM}$ & $\begin{array}{l}\text { Phase I in R/R MM and R/R AML patients (NCT02675452) } \\
\text { Phase I as a combination of AMG-176 plus Venetoclax in different R/R } \\
\text { hematologic malignancies including AML, NHL, and DLBCL (NCT03797261) }\end{array}$ \\
\hline AMG-397 & Amgen & undisclosed & $\begin{array}{l}\text { Phase I clinical trial is evaluating the safety, tolerability, pharmacokinetics, and } \\
\text { efficacy of AMG } 397 \text { in MM, AML, DLBCL, and NHL patients (NCT03465540) }\end{array}$ \\
\hline AZD5991 & AstraZeneca & $\mathrm{Ki}=0.2 \mathrm{nM}$ & $\begin{array}{l}\text { Phase I as a monotherapy in different R/R hematologic malignancies including } \\
\text { NHL, ALL, RS, SLL, T-cell lymphoma, CTCL, CLL, AML/MDS, and MM patients } \\
\text { (NCT03218683) } \\
\text { Phase II is sequential, dose-escalation study of combination AZD5991 plus } \\
\text { Venetoclax in R/R AML/MDS patients (NCT03218683) }\end{array}$ \\
\hline VU661013 & $\begin{array}{l}\text { Stephen Fesik's group at Vanderbilt } \\
\text { University }\end{array}$ & $\mathrm{Ki}=0.097 \mathrm{nM}$ & $\begin{array}{l}\text { Have partnership with Boehringer Ingelheim Company for clinical trials but no plan } \\
\text { disclosed yet. (https://www.boehringer-ingelheim.us/press-release/ } \\
\text { boehringeringelheim-and-vanderbilt-university-expand-partnership-develop- } \\
\text { novel) }\end{array}$ \\
\hline
\end{tabular}

is also considered a Mcl-1 dependent cells type (Campbell and et al., 2018). However, a reference showing A-1210477 induced apoptosis in Bcl-2 dependent cells at higher concentration when compared with Mcl-1 inhibition concentration (Koss et al., 2016). Unfortunately, no in vivo activity was associated with A-1210477, even with the most sensitive cell lines. This was attributed to cell penetration issues and reduced bioavailability due to the high levels of serum protein binding.

\section{Marinopyrrole A (Maritoclax)}

This natural agent was first discovered by Hong-Gang Wang's group at Pennsylvania State University in 2012 (Doi et al., 2012). The BH3 mimetic drug Maritoclax induces degradation of Mcl1 proteins and disrupt Mcl-1: Bim complex. Maritoclax effectively binds the site of the $\mathrm{BH} 3$-only proteins $\mathrm{p} 4$ binding site and leads to apoptosis. Further, it has been reported that this natural agent is effective against $\mathrm{Mcl}-1$ overexpressing cancer cells (Doi et al., 2012). Blocking BH3 binding site is related with increasing amount of Mcl-1 protein, followed by its ubiquitination and degradation by the E3 ligase (ubiquitin ligase) (Kaleigh and Manabu, 2013). Moreover, the treatment of Maritoclax did not result in Noxa upregulation (Doi et al., 2012). We found that Maritoclax potentiates the apoptotic response of ABT-737 in human melanoma cells (Pandey and et al., 2013).

\section{Mcl-1 Inhibitor Molecule 1 (MIM1)}

Developed in 2012 by Cohen and co-workers, polyphenol compound MIM1 acts as a semi $\mathrm{BH} 3$ mimetic which induces
Noxa (Cohen et al., 2012). MIM1 seems very similar to BH3 mimetic Mcl-1 inhibitors (Mallick and et al., 2019). This Mcl-1 inhibitor exhibited an ability to induce apoptosis in Mcl-1 dependent cells through upregulation of proapoptotic protein Noxa, which selectively inhibits Mcl-1 with high affinity binding (Smith et al., 2011; Kale et al., 2018; Mallick and et al., 2019). Also, induction of Noxa dissociates Mcl-1:Bim association complex. Unfortunately, MIM1 was only able to induce Bak dependent apoptosis at high concentrations (more than $10 \mu \mathrm{M}$ ). MIM1 failed to induce apoptosis in anti-apoptotic proteins dependent cell lines (Varadarajan et al., 2013).

\section{UMI-77}

Developed in 2013 by Zaneta Nikolovska-Coleska's group at University of Michigan, naphthol derivative UMI-77 is another semi $\mathrm{BH} 3$ mimetic Mcl-1 inhibitor with high binding affinity ( $\mathrm{Ki}=490 \mathrm{nM}$ ) (Azmi and et al., 2013; Abulwerdi et al., 2014). In order to induce apoptosis, UMI-77 was found to upregulate pro-apoptotic protein Noxa thereby selectively inhibit Mcl-1 (Mallick and et al., 2019). UMI-77 and Noxa competing for $\mathrm{Mcl}-1$ binding with $\mathrm{Bax}$ and Bak proteins ultimately disrupt the Mcl-1: Bak and Mcl-1: Bak complexes, which results in Cytochrome $\mathrm{C}$ release and Caspase 3 activation (Abulwerdi et al., 2014). The in vitro and in vivo preclinical studies demonstrated that UMI-77 potently inhibits tumor growth and induces apoptosis in MM cells (Azmi and et al., 2013), and pancreatic cancer cells lines (Abulwerdi et al., 2014), both of which rely on the Mcl-1 protein as a survival factor (Miyamoto et al., 1999; Schniewind et al., 2004; Ren et al., 2009). 
In addition to pancreatic cancer cell line BxPC-3 xenograft mouse model and MM animal xenografts, UMI-77 significantly delayed growth activity in breast cancer cell line MDA-MB-468 xenograft mouse model as well (Campbell and et al., 2018).

\section{S63845}

Developed in 2015 by a Servier and Vernalis partnership, atropisomers thienopyrimidine scaffold molecule S63845 is a selective BH3 mimetic Mcl-1 inhibitor that can activates the Bax/Bak dependent mitochondrial apoptotic pathway (Kotschy et al., 2016). S63845 is a selective and potent BH3 mimetic. It binds with high affinity to the $\mathrm{BH} 3$-binding groove of $\mathrm{Mcl}-1$ (Kd $=0.19 \mathrm{nM}$ ) without any detectable binding to Bcl-2 or Bcl-xL proteins. S63845 showed effective anti-cancer activity in its in vitro and in vivo preclinical studies (Kotschy et al., 2016). The IV infusion of S63845 once daily for five consecutive days resulted in $100 \%$ tumor regression in MM subcutaneous tumor models and lymphoma disseminated mouse model E $\mu-\mathrm{Myc}$ (Kotschy et al., 2016; Brennan et al., 2018). The same tumor regression was related with AML as well (Kotschy et al., 2016). This inhibitor had a therapeutic effect without significant weight loss apparent side effects in normal mice tissues (Kotschy et al., 2016). Along with A-1210477 and UMI-77, S63845 also inhibited growth activity of TN breast cancer cell line (Campbell and et al., 2018).

After S63845 proved its eligibility as a selective Mcl-1 antagonist, impressive studies have continued coming up. Recently in 2019, S63845 showed activity both in vitro and in vivo by killing human $\mathrm{T}$ cell acute lymphoblastic leukemia cells (T-ALL) (Li et al., 2019). It was even more potent in inducing apoptosis as a combination therapy with Venetoclax without any appreciable toxicity (Li et al., 2019). In 2020, in vitro, ex vivo, and in vivo preclinical evaluations investigated the combination of S63845 plus Venetoclax. In vitro study tested the sensitivities of five MM cell lines to the drug while the in vivo study used an aggressive disseminated model of MM. The combined finding came clearly with increasing apoptotic cell death, reduced cell survival as well as delayed tumor growth in vivo (Algarín et al., 2020). Furthermore, S63845 was evaluated in a triple combination with Venetoclax plus dexamethasone. Clearly, in vitro and in vivo studies showed that dexamethasone increased the effectiveness of both S63845 and Venetoclax. Furthermore, in vitro studies illustrated that the triple therapy is a stronger synergism than the S63845 plus Venetoclax in resistant MM cell line (MM.1S) (Algarín et al., 2020). In addition, the combination of $\mathbf{S} 63845$ and Venetoclax, enhanced the Venetoclax sensitivity and overcome resistance to Venetoclax in human myeloma cell lines (HMCLs) (Wong and Chim, 2020).

Servier and Vernalis and Novartis have created another S-derivative called S64315 or MIK666. S64315/MIK666 is in clinical trial as a single agent in $\mathrm{R} / \mathrm{R}$ lymphoma or $\mathrm{R} / \mathrm{R} \mathrm{MM}$ (NCT02992483). Furthermore, this molecule being tested in AML and myelodysplastic syndrome (MDS) patients (NCT02979366). Another clinical trial is undergoing by Servier and Vernalis in a combination with Venetoclax in AML patients (NCT03672695).

\section{AMG-176}

Developed in 2016 by Amgen, chirality macrocyclic acylsulfonamide (spiromacrocyclic) AMG-176 is an orally selective Mcl-1 inhibitor with high binding affinity $(\mathrm{Ki}=$ $0.06 \mathrm{nM}$ ), induces rapid apoptosis in different hematologic malignancies. The treatment of AMG-176 disrupts the interactions of the Mcl-1: Bak complex (Caenepeel et al., 2018; Caenepeel and et al., 2017). Preclinical studies have demonstrated that AMG-176 is non-toxic and efficacious in both MM subcutaneous xenograft models and disseminated models, inhibited 100\% tumor growth (Caenepeel et al., 2018). In preclinical studies, AMG-176 has been shown to eradicate CLL cells as a single agent or in a combination with a low dose of Venetoclax (Yi and et al., 2020). Interestingly, AMG-176 was the first selective Mcl-1 inhibitor to be studied in humans. Currently, AMG-176 is in phase I clinical trials via IV administrations in patients with $\mathrm{R} / \mathrm{R} \mathrm{MM}$ and patients with $\mathrm{R} / \mathrm{R}$ AML (NCT02675452). AMG-176 monotherapy has potent antimyeloma and unique hematologic activity resulting in marked survival improvement. Furthermore, phase I clinical trials have also evaluated AMG-176 as a combination therapy with Venetoclax which presents as an interesting therapy for different $\mathrm{R} / \mathrm{R}$ hematologic malignancies including $\mathrm{AML}$, diffuse large B cell lymphoma (DLBCL), and Non-Hodgkin's lymphoma (NHL) (NCT03797261). Furthermore, as a combination with MEK inhibitor (Trametinib), AMG-176 increased the tumor regression effect in murine models of solid tumor cell lines (Nangia et al., 2018).

Amgen has developed another potent and selective analog AM-8621, nonetheless, this molecule has poor oral bioavailability and short half-life (Caenepeel et al., 2018). Interestingly, MM cells showed sensitivity to AM-8621 as a monotherapy and as a combination therapy with dexamethasone (Caenepeel et al., 2018). Caenepeel et al. (2019) investigated the activities of AMG 176 and AM-8621 in combination with Cytarabine, Doxorubicin, and Decitabine in a preclinical models of AML (Caenepeel and et al., 2019). The other analog AMG-397 is evaluated orally in the clinic. A phase I clinical trial evaluating its safety, tolerability, pharmacokinetics, and efficacy in MM, AML, DLBCL, and NHL patients by administrating AMG-397 in a weekly cycle consisting of two consecutive days of one oral dose followed by five days off at a weekly interval (NCT03465540).

\section{AZD5991}

Developed in 2017 by AstraZeneca, indole-2-carboxylic acids analog AZD5991, is a potent and selective macrocyclic Mcl-1 inhibitor that rapidly activates Caspase proteins, which leads to apoptosis in $\mathrm{MM}$ cell lines $\left(\mathrm{GI}_{50}=10 \mathrm{nM}\right.$ ) (Hird and et al., 2017; Tron et al., 2018). AZD5991 is a BH3 mimetic with high binding affinity $(\mathrm{Ki}=0.2 \mathrm{nM})$ disrupts the Mcl-1: Bak complex (Hird and et al., 2017; Tron et al., 2018). Most notably, in a number of MM and AML mouse and rat xenograft models, AZD5991 exhibits a potent activity with the preclinical in vivo studies showing $100 \%$ tumor regression after a single IV dose in both monotherapy and in combination with Venetoclax or Bortezomib (Tron et al., 2018). The preclinical efficacy of AZD5991 is emphasized by the apoptosis and survival improvements in MM models resistant 
to Venetoclax (Hird and et al., 2017). The remarkable in vitro and in vivo anti-tumor activities of AZD5991 in both MM and AML models support its consideration as a strong clinical candidate in different Mcl-1 dependent hematologic malignancies. The number of clinical trials are ongoing with AZD5991 as a single agent or in combinations. For example, phase 1 as a monotherapy dose escalation study in several R/R hematologic malignancies including NHL, ALL, Richter syndrome (RS), small lymphocytic lymphoma (SLL), T-cell lymphoma and cutaneous T-cell lymphoma (CTCL) (NCT03218683); phase 1 as a monotherapy in expansion groups of R/R CLL, AML/MDS, and $\mathrm{MM}$ patients; and Phase 2 sequential, dose escalation study in combination with Venetoclax in $\mathrm{R} / \mathrm{R}$ AML/MDS patients (NCT03218683).

\section{VU661013}

Developed in 2017 by Stephen Fesik's group at Vanderbilt University, indole-2-carboxylic acids analog VU661013 is a potent and selective $\mathrm{BH} 3$ mimetic $\mathrm{Mcl}-1$ inhibitor with high binding affinity $(\mathrm{Ki}=0.097 \mathrm{nM})$ (Lee et al., 2017). VU661013 destabilizes the Mcl-1: Bim complex in order to initiate MOMP (Ramsey et al., 2018). VU661013 proved potency in Mcl-1 inhibition in both in vitro and in vivo studies through its induction of apoptosis in a variety of Mcl-1 dependent tumors. Furthermore, it demonstrated efficacy in combination with Venetoclax in Venetoclax resistant cells, patient derived xenografts, and murine models of AML (Ramsey et al., 2018). The further modifications of this molecule is being made to improve the efficacy and bioavailability. Another analog has been made (compound 42), which bound to Mcl-1 with picomolar affinity $(\mathrm{Ki}=70-300 \mathrm{pM})$ in order to displace Bim (Lee et al., 2019). Compound 42 showed in vivo growth inhibition in xenograft models of MM and AML (Lee et al., 2019).

\section{CONCLUSION AND FUTURE DIRECTION}

The anti-apoptotic protein Mcl-1 is critical in survival and drug resistance of several malignancies including MM (Krajewska et al., 1996; Miyamoto et al., 1999; Andersen et al., 2005; Song et al., 2005; Ding et al., 2007; Boisvert-Adamo et al., 2009; Brotin et al., 2010). Last decade or so has seen tremendous development, various Mcl-1 inhibitors have been developed. These new inhibitors may help in overcoming drug resistance and improve treatment of $\mathrm{MM}$ and other hematological malignancies where Mcl-1 is an important survival factor. The numerous $\mathrm{BH} 3$ mimetic and semi $\mathrm{BH} 3$ mimetic drugs have proved their efficacy in preclinical studies. Hopefully, after clinical trial of one of these numerous drugs receive FDA approval. It may open up a new door in the targeted MM therapy that will help to improve medical approaches, and the outcome of MM patients. Although, Mcl-1 inhibitors have good anti-myeloma activity as a monotherapy in hematological cancer models, most development strategies are focused on combination, which can increase the potential of these molecules. These combinations are shown to be especially valuable if the drug consists of a selective Mcl-1 inhibitor plus an existing drug that inhibits other anti-apoptotic proteins including $\mathrm{Bcl}-2$ and $\mathrm{Bcl}-\mathrm{xL}$, and/or drug that induce proapoptotic proteins expression. Combination therapies such as selective Bcl-2 proteins inhibitors or proteasome inhibitors (Venetoclax or Bortezomib) have been attempted to improve the therapeutic outcome (Caenepeel et al., 2018; Ramsey et al., 2018; Tron et al., 2018; Moujalled et al., 2019). Furthermore, the triple combination therapy plus dexamethasone has shown a good effect and presents as an effective strategy (Algarín et al., 2020). Interestingly, three of the recently developed BH3-mimetic are in clinical trials as a combination therapy with Venetoclax. These combination strategies allow patients to interrupt treatment for long periods of time and show a successful development for this new drug class. Based on this information, nowadays the small molecule $\mathrm{BH} 3$ mimetics and semi mimetics compounds represent the most promising approach for the selective inhibition of $\mathrm{Mcl}-1$. This places the priority on the rational design of novel $\mathrm{BH} 3$ mimetic drugs that binds extremely tightly and selectively to Mcl-1 for the better outcome of the treatment.

\section{AUTHOR CONTRIBUTIONS}

OA-O, MS, RC, WE collected the literature, made figures, tables and wrote the draft. TB-A provided clinical insight and edited the draft. SJ and BA provided chemical and inflammatory insights and modified the draft, and MP conceived the idea, provided the instructions and finally edited the manuscript.

\section{FUNDING}

This work was supported by Camden Research Initiative fund (MP, TB-A, and SJ), New Jersey Health Foundation (SJ, MP.), and inter department fund from Cooper Medical School of Rowan University, Camden, NJ (MP).

\section{ACKNOWLEDGMENTS}

This work was supported by Camden Research Initiative fund (MP, TB-A, and SJ), New Jersey Health Foundation (SJ, MP), and inter department fund from Cooper Medical School of Rowan University, Camden, NJ (MP). The authors are thankful to Kishore Challagundla for helping in figures through Biorender. com. The authors are thankful to Rachel King, Cooper Medical School of Rowan University Library for careful proofreading and editing the manuscript. 


\section{REFERENCES}

Abdi, J., Chen, G., and Chang, H. (2013). Drug Resistance in Multiple Myeloma: Latest Findings and New Concepts on Molecular Mechanisms. Oncotarget 4 (12), 2186-2207. doi:10.18632/oncotarget.1497

Abulwerdi, F., Liao, C., Liu, M., Azmi, A. S., Aboukameel, A., Mady, A. S. A., et al. (2014). A Novel Small-Molecule Inhibitor of Mcl-1 Blocks Pancreatic Cancer Growth In Vitro and In Vivo. Mol. Cancer Ther. 13 (3), 565-575. doi:10.1158/ 1535-7163.mct-12-0767

Algarín, E. M., Díaz-Tejedor, A., Mogollón, P., Hernández-García, S., Corchete, L. A., San-Segundo, L., et al. (2020). Preclinical Evaluation of the Simultaneous Inhibition of MCL-1 and BCL-2 with the Combination of S63845 and Venetoclax in Multiple Myeloma. Haematologica 105 (3), e116-e120. doi:10.3324/haematol.2018.212308

Andersen, M. H., Becker, J. C., and Thor Straten, P. (2005). The Antiapoptotic Member of the Bcl-2 Family Mcl-1 Is a CTL Target in Cancer Patients. Leukemia 19 (3), 484-485. doi:10.1038/sj.leu.2403621

Azmi, A. S., Nikolovka-Coleska, Z., Abidi, M., Marsack, K., Masood, A., Yano, H., et al. (2013). "Selective Inhibitors of Mcl-1 with Potent Activity against Multiple Myeloma Patient Cells and Animal Xenografts," in AACR 104th Annual Meeting 2013, April 6-10, 2013 (Washington, DC: AACR). doi:10.1158/ 1538-7445.am2013-3438

Bae, J., Leo, C. P., Hsu, S. Y., and Hsueh, A. J. W. (2000). MCL-1S, a Splicing Variant of the Antiapoptotic BCL-2 Family Member MCL-1, Encodes a Proapoptotic Protein Possessing Only the BH3 Domain. J. Biol. Chem. 275 (33), 25255-25261. doi:10.1074/jbc.m909826199

Bergsagel, D. E., Sprague, C. C., Austin, C., and Griffith, K. M. (1962). Evaluation of New Chemotherapeutic Agents in the Treatment of Multiple Myeloma. IV. LPhenylalanine Mustard (NSC-8806). Cancer Chemother. Rep., 21, 87-99.

Bergsagel, P. L., and Kuehl, W. M. (2005). Molecular Pathogenesis and a Consequent Classification of Multiple Myeloma. J. Clin. Oncol. 23 (26), 6333-6338. doi:10.1200/jco.2005.05.021

Bingle, C. D., Craig, R. W., Swales, B. M., Singleton, V., Zhou, P., and Whyte, M. K. B. (2000). Exon Skipping in Mcl-1 Results in a Bcl-2 Homology Domain 3 Only Gene Product that Promotes Cell Death. J. Biol. Chem. 275 (29), 22136-22146. doi:10.1074/jbc.m909572199

Boisvert-Adamo, K., Longmate, W., Abel, E. V., and Aplin, A. E. (2009). Mcl-1 Is Required for Melanoma Cell Resistance to Anoikis. Mol. Cancer Res. 7 (4), 549-556. doi:10.1158/1541-7786.mcr-08-0358

Brennan, M. S., Chang, C., Tai, L., Lessene, G., Strasser, A., Dewson, G., et al. (2018). Humanized Mcl-1 Mice Enable Accurate Preclinical Evaluation of MCL-1 Inhibitors Destined for Clinical Use. Blood 132 (15), 1573-1583. doi:10.1182/blood-2018-06-859405

Brotin, E., Meryet-Figuière, M., Simonin, K., Duval, R. E., Villedieu, M., LeroyDudal, J., et al. (2010). Bcl-XL and MCL-1 Constitute Pertinent Targets in Ovarian Carcinoma and Their Concomitant Inhibition Is Sufficient to Induce Apoptosis. Int. J. Cancer 126 (4), 885-895. doi:10.1002/ijc.24787

Caenepeel, S., Brown, S. P., Belmontes, B., Moody, G., Keegan, K. S., Chui, D., et al. (2018). AMG 176, a Selective MCL1 Inhibitor, Is Effective in Hematologic Cancer Models Alone and in Combination with Established Therapies. Cancer Discov. 8 (12), 1582-1597. doi:10.1158/2159-8290.CD-18-0387

Caenepeel, S., Belmontes, B., Osgood, T., Cajulis, E., Coxon, A., Canon, J., et al. (2019). "AMG 176 Exhibits Robust Antitumor Activity in Combination with Standard of Care Agents in Models of Acute Myeloid Leukemia," in AACR Annual Meeting 2019, March 29-April 3, 2019 (Atlanta, GA: AACR). doi:10.1158/1538-7445.am2019-2180

Caenepeel, S. R., Brown, S. P., Belmontes, B., Moody, G., Keegan, K. S., Chui, D., et al. (2017). "Preclinical Evaluation of AMG 176, a Novel, Potent and Selective Mcl-1 Inhibitor with Robust Anti-tumor Activity in Mcl-1 Dependent Cancer Models," in AACR Annual Meeting 2017, April 1-5, 2017 (Washington, DC: AACR). doi:10.1158/1538-7445.am2017-2027

Calame, K. L., Lin, K.-I., and Tunyaplin, C. (2003). Regulatorymechanisms Thatdetermine Thedevelopment Andfunction Ofplasmacells. Annu. Rev. Immunol. 21, 205-230. doi:10.1146/annurev.immunol.21.120601.141138

Campbell, K. J., Dhayade, S., Ferrari, N., Sims, A. H., Johnson, E., Mason, S. M., et al. (2018). MCL-1 Is a Prognostic Indicator and Drug Target in Breast Cancer. Cell Death Dis 9 (2), 19. doi:10.1038/s41419-017-0035-2
Chao, J.-R., Wang, J.-M., Lee, S.-F., Peng, H.-W., Lin, Y.-H., Chou, C.-H., et al. (1998). mcl-1 Is an Immediate-Early Gene Activated by the GranulocyteMacrophage colony-stimulating Factor (GM-CSF) Signaling Pathway and Is One Component of the GM-CSF Viability Response. Mol. Cel Biol 18 (8), 4883-4898. doi:10.1128/mcb.18.8.4883

Cohen, N. A., Stewart, M. L., Gavathiotis, E., Tepper, J. L., Bruekner, S. R., Koss, B., et al. (2012). A Competitive Stapled Peptide Screen Identifies a Selective Small Molecule that Overcomes MCL-1-dependent Leukemia Cell Survival. Chem. Biol. 19 (9), 1175-1186. doi:10.1016/j.chembiol.2012.07.018

Cui, J., and Placzek, W. J. (2018). Post-transcriptional Regulation of Anti-apoptotic BCL2 Family Members. Int. J. Mol. Sci. 19 (1), 308. doi:10.3390/ijms19010308

Czabotar, P. E., Lee, E. F., van Delft, M. F., Day, C. L., Smith, B. J., Huang, D. C. S., et al. (2007). Structural Insights into the Degradation of Mcl-1 Induced by BH3 Domains. Proc. Natl. Acad. Sci. 104 (15), 6217-6222. doi:10.1073/ pnas.0701297104

Czabotar, P. E., Lessene, G., Strasser, A., and Adams, J. M. (2014). Control of Apoptosis by the BCL-2 Protein Family: Implications for Physiology and Therapy. Nat. Rev. Mol. Cel Biol 15 (1), 49-63. doi:10.1038/nrm3722

Dankbar, B., Padró, T., Leo, R., Feldmann, B., Kropff, M., Mesters, R. M., et al. (2000). Vascular Endothelial Growth Factor and Interleukin-6 in Paracrine Tumor-Stromal Cell Interactions in Multiple Myeloma. Blood 95 (8), 2630-2636. doi:10.1182/blood.v95.8.2630.008k05_2630_2636

De Bruyne, E., Bos, T. J., Schuit, F., Van Valckenborgh, E., Menu, E., Thorrez, L., et al. (2010). IGF-1 Suppresses Bim Expression in Multiple Myeloma via Epigenetic and Posttranslational Mechanisms. Blood 115 (12), 2430-2440. doi:10.1182/blood-2009-07-232801

Denis, C., Sopková-de Oliveira Santos, J., Bureau, R., and Voisin-Chiret, A. S. (2020). Hot-Spots of Mcl-1 Protein. J. Med. Chem. 63 (3), 928-943. doi:10.1021/ acs.jmedchem.9b00983

Derenne, S., Monia, B., Dean, N. M., Taylor, J. K., Rapp, M.-J., Harousseau, J.-L., et al. (2002). Antisense Strategy Shows that Mcl-1 rather Than Bcl-2 or Bcl-xL Is an Essential Survival Protein of Human Myeloma Cells. Blood 100 (1), 194-199. doi:10.1182/blood.v100.1.194

Dewson, G., and Kluck, R. M. (2009). Mechanisms by Which Bak and Bax Permeabilise Mitochondria during Apoptosis. J. Cel Sci 122 (Pt 16), 2801-2808. doi:10.1242/jcs.038166

Ding, Q., He, X., Hsu, J.-M., Xia, W., Chen, C.-T., Li, L.-Y., et al. (2007). Degradation of Mcl-1 by $\beta$-TrCP Mediates Glycogen Synthase Kinase 3Induced Tumor Suppression and Chemosensitization. Mol. Cel Biol 27 (11), 4006-4017. doi:10.1128/mcb.00620-06

Ding, Q., He, X., Xia, W., Hsu, J.-M., Chen, C.-T., Li, L.-Y., et al. (2007). Myeloid Cell Leukemia-1 Inversely Correlates with Glycogen Synthase Kinase-3 $\beta$ Activity and Associates with Poor Prognosis in Human Breast Cancer. Cancer Res. 67 (10), 4564-4571. doi:10.1158/0008-5472.can-06-1788

Ding, Q., Huo, L., Yang, J.-Y., Xia, W., Wei, Y., Liao, Y., et al. (2008). Downregulation of Myeloid Cell Leukemia-1 through Inhibiting Erk/Pin 1 Pathway by Sorafenib Facilitates Chemosensitization in Breast Cancer. Cancer Res. 68 (15), 6109-6117. doi:10.1158/0008-5472.can-08-0579

Doi, K., Li, R., Sung, S.-S., Wu, H., Liu, Y., Manieri, W., et al. (2012). Discovery of Marinopyrrole A (Maritoclax) as a Selective Mcl-1 Antagonist that Overcomes ABT-737 Resistance by Binding to and Targeting Mcl-1 for Proteasomal Degradation. J. Biol. Chem. 287 (13), 10224-10235. doi:10.1074/ jbc.m111.334532

Domina, A. M., Vrana, J. A., Gregory, M. A., Hann, S. R., and Craig, R. W. (2004). MCL1 Is Phosphorylated in the PEST Region and Stabilized upon ERK Activation in Viable Cells, and at Additional Sites with Cytotoxic Okadaic Acid or Taxol. Oncogene 23 (31), 5301-5315. doi:10.1038/ sj.onc. 1207692

Fiskus, W., Cai, T., DiNardo, C. D., Kornblau, S. M., Borthakur, G., Kadia, T. M., et al. (2019). Superior Efficacy of Cotreatment with BET Protein Inhibitor and BCL2 or MCL1 Inhibitor against AML Blast Progenitor Cells. Blood Cancer J. 9 (2), 1-13. doi:10.1038/s41408-018-0165-5

Gerecke, C., Fuhrmann, S., Strifler, S., Schmidt-Hieber, M., Einsele, H., and Knop, S. (2016). The Diagnosis and Treatment of Multiple Myeloma. Dtsch Arztebl Int. 113 (27-28), 470-476. doi:10.3238/arztebl.2016.0470

Gomez-Bougie, P., Bataille, R. g., and Amiot, M. (2004). The Imbalance between Bim and Mcl-1 Expression Controls the Survival of Human Myeloma Cells. Eur. J. Immunol. 34 (11), 3156-3164. doi:10.1002/eji.200424981 
Gomez-Bougie, P., Maiga, S., Tessoulin, B., Bourcier, J., Bonnet, A., Rodriguez, M. S., et al. (2018). BH3-mimetic Toolkit Guides the Respective Use of BCL2 and MCL1 BH3-Mimetics in Myeloma Treatment. J. Am. Soc. Hematol. 132 (25), 2656-2669. doi:10.1182/blood-2018-03-836718

Harley, M. E., Allan, L. A., Sanderson, H. S., and Clarke, P. R. (2010). Phosphorylation of Mcl-1 by CDK1-Cyclin B1 Initiates its Cdc20-dependent Destruction during Mitotic Arrest. EMBO J. 29 (14), 2407-2420. doi:10.1038/ emboj. 2010.112

Herndon, T. M., Deisseroth, A., Kaminskas, E., Kane, R. C., Koti, K. M., Rothmann, M. D., et al. (2013). US Food and Drug Administration Approval: Carfilzomib for the Treatment of Multiple Myeloma. Clinical cancer research, 19(17), 4559-4563.

Herrant, M., Jacquel, A., Marchetti, S., Belhacène, N., Colosetti, P., Luciano, F., et al. (2004). Cleavage of Mcl-1 by Caspases Impaired its Ability to Counteract BimInduced Apoptosis. Oncogene 23 (47), 7863-7873. doi:10.1038/sj.onc.1208069

Hideshima, T., Chauhan, D., Shima, Y., Raje, N., Davies, F. E., Tai, Y. T., et al. (2000). Thalidomide and its Analogs Overcome Drug Resistance of Human Multiple Myeloma Cells to Conventional Therapy. Blood, 96(9), 2943-2950.

Hird, A. W., Secrist, P. J., Adam, A., Belmonte, M. A., Gangl, E., Gibbons, F., et al. (2017). "Abstract DDT01-02: AZD5991: A Potent and Selective Macrocyclic Inhibitor of Mcl-1 for Treatment of Hematologic Cancers," in AACR Annual Meeting 2017, April 1-5, 2017 (Washington, DC: AACR). doi:10.1158/15387445.am2017-ddt01-02

Huang, H.-M., Huang, C.-J., and Yen, J. J.-Y. (2000). Mcl-1 Is a Common Target of Stem Cell Factor and Interleukin-5 for Apoptosis Prevention Activity via MEK/ MAPK and PI-3K/Akt Pathways. Blood 96 (5), 1764-1771. doi:10.1182/ blood.v96.5.1764

Inoshita, S., Takeda, K., Hatai, T., Terada, Y., Sano, M., Hata, J., et al. (2002). Phosphorylation and Inactivation of Myeloid Cell Leukemia 1 by JNK in Response to Oxidative Stress. J. Biol. Chem. 277 (46), 43730-43734. doi:10.1074/jbc.m207951200

Inuzuka, H., Shaik, S., Onoyama, I., Gao, D., Tseng, A., Maser, R. S., et al. (2011). SCFFBW7 Regulates Cellular Apoptosis by Targeting MCL1 for Ubiquitylation and Destruction. Nature 471 (7336), 104-109. doi:10.1038/nature09732

Jourdan, M., De Vos, J., Mechti, N., and Klein, B. (2000). Regulation of Bcl-2Family Proteins in Myeloma Cells by Three Myeloma Survival Factors: Interleukin-6, Interferon-Alpha and Insulin-like Growth Factor 1. Cell Death Differ 7 (12), 1244-1252. doi:10.1038/s..cdd.4400758

Kale, J., Osterlund, E. J., and Andrews, D. W. (2018). BCL-2 Family Proteins: Changing Partners in the Dance towards Death. Cel Death Differ 25 (1), 65-80. doi:10.1038/cdd.2017.186

Kaleigh, F., and Manabu, K. (2013). Evading Apoptosis in Cancer. Trends Cel Biol 23, 620-633. doi:10.1016/j.tcb.2013.07.006

Kaufmann, T., Strasser, A., and Jost, P. J. (2012). Fas Death Receptor Signalling: Roles of Bid and XIAP. Cel Death Differ 19 (1), 42-50. doi:10.1038/ cdd.2011.121

Kazandjian, D. (2016). Multiple Myeloma Epidemiology and Survival: A Unique Malignancy. Semin. Oncol. 43 (6), 676-681. doi:10.1053/ j.seminoncol.2016.11.004

Kim, J.-H., Sim, S.-H., Ha, H.-J., Ko, J.-J., Lee, K., and Bae, J. (2009). MCL-1ES, a Novel Variant of MCL-1, Associates with MCL-1L and Induces Mitochondrial Cell Death. FEBS Lett. 583 (17), 2758-2764. doi:10.1016/j.febslet.2009.08.006

Klein, B., Zhang, X., Lu, Z., and Bataille, R. (1995). Interleukin-6 in Human Multiple Myeloma. Blood 85 (4), 863-872. doi:10.1182/ blood.v85.4.863.bloodjournal854863

Koss, B., Ryan, J., Budhraja, A., Szarama, K., Yang, X., Bathina, M., et al. (2016). Defining Specificity and On-Target Activity of BH3-Mimetics Using Engineered B-ALL Cell Lines. Oncotarget 7 (10), 11500-11511. doi:10.18632/oncotarget.7204

Kotschy, A., Szlavik, Z., Murray, J., Davidson, J., Maragno, A. L., Le ToumelinBraizat, G., et al. (2016). The MCL1 Inhibitor S63845 Is Tolerable and Effective in Diverse Cancer Models. Nature 538 (7626), 477-482. doi:10.1038/ nature19830

Kozopas, K. M., Yang, T., Buchan, H. L., Zhou, P., and Craig, R. W. (1993). MCL1, a Gene Expressed in Programmed Myeloid Cell Differentiation, Has Sequence Similarity to BCL2. Proc. Natl. Acad. Sci. 90 (8), 3516-3520. doi:10.1073/ pnas. 90.8 .3516
Krajewska, M., Krajewski, S., Epstein, J. I., Shabaik, A., Sauvageot, J., Song, K., et al. (1996). Immunohistochemical Analysis of Bcl-2, Bax, Bcl-X, and Mcl-1 Expression in Prostate Cancers. Am. J. Pathol. 148 (5), 1567-1576.

Kumar, S. K., Rajkumar, S. V., Dispenzieri, A., Lacy, M. Q., Hayman, S. R., Buadi, F. K., et al. (2008). Improved Survival in Multiple Myeloma and the Impact of Novel Therapies. Blood 111 (5), 2516-2520. doi:10.1182/blood-2007-10-116129

Lacy, M. Q., Hayman, S. R., Gertz, M. A., Dispenzieri, A., Buadi, F., Kumar, S., et al. (2009). Pomalidomide (CC4047) Plus Low-Dose Dexamethasone as Therapy for Relapsed Multiple Myeloma. J Clin Oncol, 27(30), 5008-5014.

Laubach, J. P., Moreau, P., San-Miguel, J. F., and Richardson, P. G. (2015). Panobinostat for the Treatment of Multiple Myeloma. Clin. Cancer Research, 21(21), 4767-4773.

Le Gouill, S., Podar, K., Amiot, M., Hideshima, T., Chauhan, D., Ishitsuka, K., et al. (2004). VEGF Induces Mcl-1 Up-Regulation and Protects Multiple Myeloma Cells against Apoptosis. Blood 104 (9), 2886-2892. doi:10.1182/blood-2004-051760

Lee, T., Bian, Z., Zhao, B., Hogdal, L. J., Sensintaffar, J. L., Goodwin, C. M., et al. (2017). Discovery and Biological Characterization of Potent Myeloid Cell Leukemia-1 Inhibitors. FEBS Lett. 591 (1), 240-251. doi:10.1002/18733468.12497

Lee, T., Christov, P. P., Shaw, S., Tarr, J. C., Zhao, B., Veerasamy, N., et al. (2019). Discovery of Potent Myeloid Cell Leukemia-1 (Mcl-1) Inhibitors that Demonstrate In Vivo Activity in Mouse Xenograft Models of Human Cancer. J. Med. Chem. 62 (8), 3971-3988. doi:10.1021/acs.jmedchem.8b01991

Leu, C.-M., Chang, C., and Hu, C.-p. (2000). Epidermal Growth Factor (EGF) Suppresses Staurosporine-Induced Apoptosis by Inducing Mcl-1 via the Mitogen-Activated Protein Kinase Pathway. Oncogene 19 (13), 1665-1675. doi:10.1038/sj.onc.1203452

Leuenroth, S. J., Grutkoski, P. S., Ayala, A., and Simms, H. H. (2000). The Loss of Mcl-1 Expression in Human Polymorphonuclear Leukocytes Promotes Apoptosis. J. Leukoc. Biol. 68 (1), 158-166. doi:10.1189/jlb.68.1.158

Leverson, J. D., Zhang, H., Chen, J., Tahir, S. K., Phillips, D. C., Xue, J., et al. (2015). Potent and Selective Small-Molecule MCL-1 Inhibitors Demonstrate OnTarget Cancer Cell Killing Activity as Single Agents and in Combination with ABT-263 (Navitoclax). Cel Death Dis 6, e1590. doi:10.1038/cddis.2014.561

Li, Z., He, S., and Look, A. T. (2019). The MCL1-specific Inhibitor S63845 Acts Synergistically with venetoclax/ABT-199 to Induce Apoptosis in T-Cell Acute Lymphoblastic Leukemia Cells. Leukemia 33 (1), 262-266. doi:10.1038/s41375018-0201-2

Liang, H., and Fesik, S. W. (1997). Three-dimensional Structures of Proteins Involved in Programmed Cell Death. J. Mol. Biol. 274 (3), 291-302. doi:10.1006/ jmbi.1997.1415

Lin, F.-R., Kuo, H.-K., Ying, H.-Y., Yang, F.-H., and Lin, K.-I. (2007). Induction of Apoptosis in Plasma Cells by B Lymphocyte Induced Maturation Protein-1 Knockdown. Cancer Res. 67 (24), 11914-11923. doi:10.1158/0008-5472.can-071868

Lokhorst, H. M., Plesner, T., Laubach, J. P., Nahi, H., Gimsing, P., Hansson, M., et al. (2015). Targeting CD38 with Daratumumab Monotherapy in Multiple Myeloma. N. Engl. J. Med., 373(13), 1207-1219.

Lonial, S., Dimopoulos, M., Palumbo, A., White, D., Grosicki, S., Spicka, I., et al. (2015). Elotuzumab Therapy for Relapsed or Refractory Multiple Myeloma. $N$. Engl. J. Med., 373(7), 621-631.

Magiera, M. M., Mora, S., Mojsa, B., Robbins, I., Lassot, I., and Desagher, S. (2013). Trim17-mediated Ubiquitination and Degradation of Mcl-1 Initiate Apoptosis in Neurons. Cel Death Differ 20 (2), 281-292. doi:10.1038/cdd.2012.124

Mallick, D. J., Soderquist, R. S., Bates, D., and Eastman, A. (2019). Confounding Off-Target Effects of $\mathrm{BH} 3$ Mimetics at Commonly Used Concentrations: MIM1, UMI-77, and A-1210477. Cel Death Dis 10 (3), 185. doi:10.1038/ s41419-019-1426-3

Maurer, U., Charvet, C., Wagman, A. S., Dejardin, E., and Green, D. R. (2006). Glycogen Synthase Kinase-3 Regulates Mitochondrial Outer Membrane Permeabilization and Apoptosis by Destabilization of MCL-1. Mol. Cel 21 (6), 749-760. doi:10.1016/j.molcel.2006.02.009

Miyamoto, Y., Hosotani, R., Wada, M., Lee, J.-U., Koshiba, T., Fujimoto, K., et al. (1999). Immunohistochemical Analysis of Bcl-2, Bax, Bcl-X, and Mcl-1 Expression in Pancreatic Cancers. Oncology 56 (1), 73-82. doi:10.1159/ 000011933 
Mojsa, B., Lassot, I., and Desagher, S. (2014). Mcl-1 Ubiquitination: Unique Regulation of an Essential Survival Protein. Cells 3 (2), 418-437. doi:10.3390/cells3020418

Moreaux, J., Legouffe, E., Jourdan, E., Quittet, P., Rème, T., Lugagne, C., et al. (2004). BAFF and APRIL Protect Myeloma Cells from Apoptosis Induced by Interleukin 6 Deprivation and Dexamethasone. Blood 103 (8), 3148-3157. doi:10.1182/blood-2003-06-1984

Moujalled, D. M., Pomilio, G., Ghiurau, C., Ivey, A., Salmon, J., Rijal, S., et al. (2019). Combining BH3-Mimetics to Target Both BCL-2 and MCL1 Has Potent Activity in Pre-clinical Models of Acute Myeloid Leukemia. Leukemia 33 (4), 905-917. doi:10.1038/s41375-018-0261-3

Mukherjee, N., Strosnider, A., Vagher, B., Lambert, K. A., Slaven, S., Robinson, W. A., et al. (2018). BH3 Mimetics Induce Apoptosis Independent of DRP-1 in Melanoma. Cel Death Dis. 9 (9), 1-12. doi:10.1038/s41419-018-0932-z

Muz, B., Ghazarian, R. N., Ou, M., Luderer, M. J., Kusdono, H. D., and Azab, A. K. (2016). Spotlight on Ixazomib: Potential in the Treatment of Multiple Myeloma. Drug Des. Dev. Ther., 10, 217.

Nangia, V., Siddiqui, F. M., Caenepeel, S., Timonina, D., Bilton, S. J., Phan, N., et al. (2018). Exploiting MCL1 Dependency with Combination MEK + MCL1 Inhibitors Leads to Induction of Apoptosis and Tumor Regression in KRAS-Mutant Non-small Cell Lung Cancer. Cancer Discov. 8 (12), 1598-1613. doi:10.1158/2159-8290.cd-18-0277

Naymagon, L., and Abdul-Hay, M. (2016). Novel Agents in the Treatment of Multiple Myeloma: a Review about the Future. J. Hematol. Oncol. 9 (1), 52. doi:10.1186/s13045-016-0282-1

Ogata, A., Chauhan, D., Teoh, G., Treon, S. P., Urashima, M., Schlossman, R. L., et al. (1997). IL-6 Triggers Cell Growth via the Ras-dependent MitogenActivated Protein Kinase cascade. J. Immunol. 159 (5), 2212-2221.

Pandey, M. K., Gowda, K., Doi, K., Sharma, A. K., Wang, H. G., and Shantu, A. (2013). Proteasomal Degradation of Mcl-1 by Maritoclax Induces Apoptosis and Enhances the Efficacy of ABT-737 in Melanoma Cells. PLoS One 8 (11), e78570. doi:10.1371/journal.pone.0078570

Pawlyn, C., and Morgan, G. J. (2017). Evolutionary Biology of High-Risk Multiple Myeloma. Nat. Rev. Cancer 17 (9), 543-556. doi:10.1038/nrc.2017.63

Puthier, D., Bataille, R., and Amiot, M. (1999). IL-6 Up-Regulates Mcl-1 in Human Myeloma Cells through JAK/STAT rather Than Ras/MAP Kinase Pathway. Eur. J. Immunol. 29 (12), 3945-3950. doi:10.1002/(sici)1521-4141(199912)29: $12<3945$ ::aid-immu3945>3.0.co;2-o

Rajkumar, S. V., Hayman, S. R., Lacy, M. Q., Dispenzieri, A., Geyer, S. M., et al. (2005). Combination Therapy with Lenalidomide Plus Dexamethasone (Rev/ Dex) for Newly Diagnosed Myeloma. Blood, 106(13), 4050-4053. doi:10.1182/ blood-2005-07-2817

Ramsey, H. E., Fischer, M. A., Lee, T., Gorska, A. E., Arrate, M. P., Fuller, L., et al. (2018). A Novel MCL1 Inhibitor Combined with Venetoclax Rescues Venetoclax-Resistant Acute Myelogenous Leukemia. Cancer Discov. 8 (12), 1566-1581. doi:10.1158/2159-8290.cd-18-0140

Ren, L.-N., Li, Q.-F., Xiao, F.-J., Yan, J., Yang, Y.-F., Wang, L.-S., et al. (2009). Endocrine Glands-Derived Vascular Endothelial Growth Factor Protects Pancreatic Cancer Cells from Apoptosis via Upregulation of the Myeloid Cell Leukemia-1 Protein. Biochem. Biophysical Res. Commun. 386 (1), 35-39. doi:10.1016/j.bbrc.2009.05.149

Richardson, P. G., Barlogie, B., Berenson, J., Singhal, S., Jagannath, S., Irwin, D., et al. (2003). A Phase 2 Study of Bortezomib in Relapsed, Refractory Myeloma. N. Engl. J. Med., 348(26), 2609-2617. doi:10.1056/NEJMoa030288

Richardson, P. G., Schlossman, R. L., Weller, E., Hideshima, T., Mitsiades, C., Davies, F., et al. (2002). Immunomodulatory Drug CC-5013 Overcomes Drug Resistance and is Well Tolerated in Patients with Relapsed Multiple Myeloma. Blood, 100(9), 3063-3067. doi:10.1182/blood-2002-03-0996

Rogers, S., Wells, R., and Rechsteiner, M. (1986). Amino Acid Sequences Common to Rapidly Degraded Proteins: the PEST Hypothesis. Science 234 (4774), 364-368. doi:10.1126/science.2876518

Schniewind, B., Christgen, M., Kurdow, R., Haye, S., Kremer, B., Kalthoff, H., et al. (2004). Resistance of Pancreatic Cancer to Gemcitabine Treatment Is Dependent on Mitochondria-Mediated Apoptosis. Int. J. Cancer 109 (2), 182-188. doi:10.1002/ijc.11679

Schwickart, M., Huang, X., Lill, J. R., Liu, J., Ferrando, R., French, D. M., et al. (2010). Deubiquitinase USP9X Stabilizes MCL1 and Promotes Tumour Cell Survival. Nature 463 (7277), 103-107. doi:10.1038/nature08646
Sedlak, T. W., Oltvai, Z. N., Yang, E., Wang, K., Boise, L. H., Thompson, C. B., et al. (1995). Multiple Bcl-2 Family Members Demonstrate Selective Dimerizations with Bax. Proc. Natl. Acad. Sci. 92 (17), 7834-7838. doi:10.1073/ pnas.92.17.7834

Senichkin, V. V., Streletskaia, A. Y., Gorbunova, A. S., Zhivotovsky, B., and Kopeina, G. S. (2020). Saga of Mcl-1: Regulation from Transcription to Degradation. Cel Death Differ 27 (2), 405-419. doi:10.1038/s41418-0190486-3

Shah, V., Sherborne, A. L., Walker, B. A., Johnson, D. C., Boyle, E. M., Ellis, S., et al. (2018). Prediction of Outcome in Newly Diagnosed Myeloma: a Meta-Analysis of the Molecular Profiles of 1905 Trial Patients. Leukemia 32 (1), 102-110. doi:10.1038/leu.2017.179

Siegel, R. L., Miller, K. D., Fuchs, H. E., and Jemal, A. (2021). Cancer Statistics, 2021. CA A. Cancer J. Clin. 71 (1), 7-33. doi:10.3322/caac.21654

Singhal, S., Mehta, J., Desikan, R., Ayers, D., Roberson, P., Eddlemon, P., et al. (1999). Antitumor Activity of Thalidomide in Refractory Multiple Myeloma. $N$. Engl. J. Med., 341(21), 1565-1571. doi:10.1056/NEJM199911183412102

Slomp, A., Moesbergen, L. M., Gong, J.-n., Cuenca, M., von dem Borne, P. A., Sonneveld, P., et al. (2019). Multiple Myeloma with 1q21 Amplification Is Highly Sensitive to MCL-1 Targeting. Blood Adv. 3 (24), 4202-4214. doi:10.1182/bloodadvances.2019000702

Smith, A. J., Dai, H., Correia, C., Takahashi, R., Lee, S.-H., Schmitz, I., et al. (2011). Noxa/Bcl-2 Protein Interactions Contribute to Bortezomib Resistance in Human Lymphoid Cells. J. Biol. Chem. 286 (20), 17682-17692. doi:10.1074/ jbc.m110.189092

Song, L., Coppola, D., Livingston, S., Cress, W. D., and Haura, E. B. (2005). Mcl-1 Regulates Survival and Sensitivity to Diverse Apoptotic Stimuli in Human Nonsmall Cell Lung Cancer Cells. Cancer Biol. Ther. 4 (3), 267-276. doi:10.4161/ cbt.4.3.1496

Stewart, M. L., Fire, E., Keating, A. E., and Walensky, L. D. (2010). The MCL-1 BH3 helix Is an Exclusive MCL-1 Inhibitor and Apoptosis Sensitizer. Nat. Chem. Biol. 6 (8), 595-601. doi:10.1038/nchembio.391

Thomas, L. W., Lam, C., and Edwards, S. W. (2010). Mcl-1; the Molecular Regulation of Protein Function. FEBS Lett. 584 (14), 2981-2989. doi:10.1016/j.febslet.2010.05.061

Tiedemann, R. E., Zhu, Y. X., Schmidt, J., Shi, C. X., Sereduk, C., Yin, H., et al. (2012). Identification of Molecular Vulnerabilities in Human Multiple Myeloma Cells by RNA Interference Lethality Screening of the Druggable Genome. Cancer Res. 72 (3), 757-768. doi:10.1158/0008-5472.can-11-2781

Tron, A. E., Belmonte, M. A., Adam, A., Aquila, B. M., Boise, L. H., Chiarparin, E., et al. (2018). Discovery of Mcl-1-specific Inhibitor AZD5991 and Preclinical Activity in Multiple Myeloma and Acute Myeloid Leukemia. Nat. Commun. 9 (1), 5341. doi:10.1038/s41467-018-07551-w

Varadarajan, S., Vogler, M., Butterworth, M., Dinsdale, D., Walensky, L. D., and Cohen, G. M. (2013). Evaluation and Critical Assessment of Putative MCL-1 Inhibitors. Cel Death Differ 20 (11), 1475-1484. doi:10.1038/cdd.2013.79

Vogl, D. T., Dingli, D., Cornell, R. F., Huff, C. A., Jagannath, S., Bhutani, D., et al. (2018). Selective Inhibition of Nuclear Export With Oral Selinexor for Treatment of Relapsed or Refractory Multiple Myeloma. J. Clin. Oncol., 36(9), 859

Wang, J.-M., Chao, J.-R., Chen, W., Kuo, M.-L., Yen, J. J.-Y., and Yang-Yen, H.-F. (1999). The Antiapoptotic Gene Mcl-1 Is Up-Regulated by the Phosphatidylinositol 3-kinase/Akt Signaling Pathway through a Transcription Factor Complex Containing CREB. Mol. Cel Biol 19 (9), 6195-6206. doi:10.1128/mcb.19.9.6195

Wang, Y., Chao, J. R., Chen, W., Kuo, M. L., Yen, J. J. Y., and Yang-Yen, H. (2020). Anti-apoptotic Capacity of Mcl-1 1 127. Biochem. Biophysical Res. Commun. 526 (4), 1042-1048. doi:10.1016/j.bbrc.2020.03.181

Willis, S. N., Chen, L., Dewson, G., Wei, A., Naik, E., Fletcher, J. I., et al. (2005). Proapoptotic Bak Is Sequestered by Mcl-1 and Bcl-xL, but Not Bcl-2, until Displaced by BH3-Only Proteins. Genes Develop. 19 (11), 1294-1305. doi:10.1101/gad.1304105

Wong, K. Y., and Chim, C. S. (2020). Venetoclax, Bortezomib and S63845, an MCL1 Inhibitor, in Multiple Myeloma. J. Pharm. Pharmacol. 72 (5), 728-737. doi:10.1111/jphp.13240

Wuillème-Toumi, S., Robillard, N., Gomez, P., Moreau, P., Le Gouill, S., AvetLoiseau, H., et al. (2005). Mcl-1 Is Overexpressed in Multiple Myeloma and Associated with Relapse and Shorter Survival. Leukemia 19 (7), 1248-1252. doi:10.1038/sj.leu.2403784 
Yang, T., Kozopas, K. M., and Craig, R. W. (1995). The Intracellular Distribution and Pattern of Expression of Mcl-1 Overlap with, but Are Not Identical to, Those of Bcl-2. J. Cel Biol 128 (6), 1173-1184. doi:10.1083/jcb.128.6.1173

Yang, Y., Li, F., Saha, M. N., Abdi, J., Qiu, L., and Chang, H. (2015). miR-137 and miR197 Induce Apoptosis and Suppress Tumorigenicity by Targeting MCL-1 in Multiple Myeloma. Clin. Cancer Res. 21 (10), 2399-2411. doi:10.1158/1078-0432.ccr-14-1437

Yi, X., Sarkar, A., Kismali, G., Aslan, B., Ayres, M., Iles, L. R., et al. (2020). AMG-176, an Mcl-1 Antagonist, Shows Preclinical Efficacy in Chronic Lymphocytic Leukemia. Clin. Cancer Res. 26 (14), 3856-3867. doi:10.1158/1078-0432.CCR-19-1397

Zhang, B., Gojo, I., and Fenton, R. G. (2002). Myeloid Cell Factor-1 Is a Critical Survival Factor for Multiple Myeloma. Blood 99 (6), 1885-1893. doi:10.1182/ blood.v99.6.1885

Zhang, Y.-K., Wang, H., Leng, Y., Li, Z.-L., Yang, Y.-F., Xiao, F.-J., et al. (2011). Overexpression of microRNA-29b Induces Apoptosis of Multiple Myeloma Cells through Down Regulating Mcl-1. Biochem. biophysical Res. Commun. 414 (1), 233-239. doi:10.1016/j.bbrc.2011.09.063
Zhong, Q., Gao, W., Du, F., and Wang, X. (2005). Mule/ARF-BP1, a BH3-Only E3 Ubiquitin Ligase, Catalyzes the Polyubiquitination of Mcl-1 and Regulates Apoptosis. Cell 121 (7), 1085-1095. doi:10.1016/j.cell.2005.06.009

Conflict of Interest: The authors declare that the research was conducted in the absence of any commercial or financial relationships that could be construed as a potential conflict of interest.

Copyright (C) 2021 Al-Odat, von Suskil, Chitren, Elbezanti, Srivastava, BudakAlpddogan, Jonnalagadda, Aggarwal and Pandey. This is an open-access article distributed under the terms of the Creative Commons Attribution License (CC BY). The use, distribution or reproduction in other forums is permitted, provided the original author(s) and the copyright owner(s) are credited and that the original publication in this journal is cited, in accordance with accepted academic practice. No use, distribution or reproduction is permitted which does not comply with these terms. 